Original Article

\title{
Awareness, perceptions and beliefs about physiotherapy held by physicians working in Saudi Arabia: a cross-sectional study
}

\author{
Einas S. Al-Eisa, PhD ${ }^{1)}$, Hind Al-Hoqail, BSc ${ }^{2)}$, Asma S. Al-Rushud, MSc ${ }^{2)}$, \\ Azhar Al-Harthi, BSc ${ }^{2)}$, Banan Al-Mass, BSc ${ }^{2}$, Bashayer M. Al-Harbi, BSc ${ }^{2}$, \\ Sara Al-Azzaz, BSc ${ }^{2)}$, Ahmad H. Alghadir, PhD ${ }^{1)}$, Zaheen A. Iqbal, MPT ${ }^{1)^{*}}$ \\ 1) Rehabilitation Research Chair, College of Applied Medical Sciences, King Saud University: Riyadh, \\ Kingdom of Saudi Arabia \\ 2) Department of Rehabilitation Sciences, College of Applied Medical Sciences, King Saud University, \\ Kingdom of Saudi Arabia
}

\begin{abstract}
Purpose] Over the years physiotherapy has been recognized as a popular mode of treatment that decreases the disability and dependency rate of patients. However, there is still a need for its recognition in multidisciplinary health care structures. If a physician were well aware of how a physical therapist could help with treatment if patients and prevent complications, hospital patient load could be decreased to a greater extent. The aim of this study was to study the awareness, perception and beliefs of physicians working in Saudi Arabia about physiotherapy. [Subjects and Methods] Three hundred fifteen members of the Saudi Commission for Health Specialties (SCFHS) with different specialties, nationalities, designation, and work experience, working in various hospitals in 5 regions of Saudi Arabia were invited to participate in this study. A 22-item questionnaire was used for data collection including sections on physicians' demographics, educational levels and knowledge about physiotherapy. [Results] After applying the inclusion and exclusion criteria, data from 280 respondents was used for analysis. Seventy-five percent of respondents reported to having some knowledge of physiotherapy, and $11 \%$ of them referred patients to physiotherapy departments regularly, while $14 \%$ referred patients occasionally. To the best of our knowledge, this is first study performed in Saudi Arabia to evaluate awareness of physicians about the physiotherapy profession. [Conclusion] The results of this study highlight the need to organize various workshops and lectures about the effectiveness of physiotherapy in various diseases for physicians, on a regular basis, to update them with evidence-based treatment. It is the responsibility of physical therapists to raise the perceptions of other healthcare professionals about their profession.

Key words: Awareness, Physiotherapy, Physicians
\end{abstract}

(This article was submitted May 30, 2016, and was accepted Sep. 2, 2016)

\section{INTRODUCTION}

Physiotherapy (PT) has been recognized as a mode of treatment over the years and is rapidly growing as a profession, especially in developing countries ${ }^{1,2}$. According to the US Department of Labor, physical therapists are primary health care professionals who diagnose and treat patients of all ages ${ }^{3}$. Various subspecialties of PT have been recognized including cardiovascular and pulmonary, orthopedics, neurology, sports, etc. ${ }^{4}$, which treat a variety of patients to decrease disability and dependency ${ }^{5}$.

With increases in the disabled population and life expectancy, disability has been reported to be one of the most imperative

*Corresponding author. Zaheen Ahmed Iqbal (E-mail: Z_iqbal001@yahoo.com)

(C2016 The Society of Physical Therapy Science. Published by IPEC Inc.

This is an open-access article distributed under the terms of the Creative Commons Attribution Non-Commercial No Derivatives (by-nc-nd) License $<$ http://creativecommons.org/licenses/by-nc-nd/4.0/>. 
social and economic medical issues in Saudi Arabia (SA) ${ }^{6}$. This emphasizes the need for the development and recognition of PT in multidisciplinary healthcare structures. PT was introduced to SA a little later than the rest of the world ${ }^{7)}$ and is still at the development stage. For professional growth, it needs support from fellow healthcare practitioners, who should be aware of role of PT professionals ${ }^{3)}$. If a physician were well informed about how PT could help the treatment of patients and prevent the development of complications, hospital stays could be decreased to a larger extent $\left.{ }^{2}, 3\right)$, decreasing the burden on the healthcare system. In order to deliver effective patient care, communication, cooperation and agreement between physicians and physical therapists is essential ${ }^{8}$. Patients need a physicians' referral to see a physical therapist, and physicians are dominant and take decisions for other health care professionals ${ }^{9,10)}$. Perceptions of physicians about PT affects the treatment received by the patient ${ }^{11,12)}$.

To the best of our knowledge, no study has been performed in SA that has evaluated the awareness of physicians about the PT profession. Hence, we decided to study awareness, perception and beliefs about PT among physicians working in SA. The results of this study should help to bridge the gap in the healthcare system and suggest ways for the development of the PT profession in SA for ideal patient care.

\section{SUBJECTS AND METHODS}

Three hundred and fifteen members of the Saudi Commission for Health Specialties (SCFHS) with various specialties, nationalities, designation, and work experience, working in various hospitals in 5 regions of Saudi Arabia were invited to participate in this study. After exclusion of interns, academicians and incomplete questionnaires, 280 respondents were included in the study.

The questionnaire used for data collection was based on similar studies done in other countries ${ }^{3,8,9,11)}$. It was first sent to two senior physical therapists who were experts in research design for their feedback. It was also sent to 10 physicians for a pilot study to ensure that the questions were clear and easily understood by the respondents. Minor revisions were done in light of suggestions received and local culture.

A 22-item questionnaire was finalized for data collection. It included various sections about physicians' demographics, educational levels and knowledge about PT. It also included questions about physician's attitudes and perceptions concerning PT as a profession and their beliefs about physical therapists' ability to treat patients.

First, in order to reach respondents working in different regions of the country, this study was extensively promoted on various social networking sites highlighting its purpose and objectives. The questionnaire was then placed online and an invitation to participate in the study along with an explanation of its importance, and a link to the questionnaire was sent to physicians via email. This study was conducted between March and April 2014 by PT undergraduate students. Participants had to complete the questionnaire before the deadline and their response was considered as consent to participate in the study. All ethical permissions were obtained from the institutional review board of King Saud University.

The Statistical Package for Social sciences (SPSS) 21 program was used for data analysis. Descriptive statistics including frequencies and percentages were used for demographic data. The level of referral with regard to physicians' experience and specialty, education, and work hospital was calculated by cross-tab analysis. To assess physicians' perceptions and beliefs, descriptive analysis was done using frequencies and percentages.

\section{RESULTS}

Of the 280 respondents, $29 \%$ were females while $71 \%$ were males: $46 \%$ were residents, $30 \%$ consultants, $21 \%$ registrars and $3 \%$ professors. The majority of the respondents $(50 \%)$ had work experience of $1-5$ years. Most of the respondents $(60 \%)$ reported working in the central region of SA. Respondents who reported working in government and military hospitals were of $30 \%$ and $20 \%$ of the total, respectively. The distribution of respondents on the basis of their specialty is shown in Table 1 .

Fifty-one percent of respondents reported having some knowledge of PT. Respondents who reported attending awareness lectures about PT or had received special training on cases that can benefit from PT seem to have been more aware than other respondents. In all, $17 \%$ of the respondents reported attending awareness lectures about PT. Among these, $15 \%$ reported referring patients to PT departments regularly. On the other hand, 10\% of those who didn't attend any lecture about PT reported referring patients to PT departments. Similarly, among 35\% of respondents who reported receiving special training on cases that can benefit from PT, 20\% reported referring patients to PT departments regularly (Table 2).

Among those who reported referring patients to PT departments regularly, at least $50 \%$ reported receiving PT education in their medical school. Besides this, $41 \%$ of respondents also reported that they knew about the various specializations of PT.

Out of 280 respondents, $11 \%$ reported referring patients to PT departments regularly when necessary, while $49 \%$ reported that they never referred patients to a PT department. Among the remainder, 26\% reported referring patients rarely, and 14\% occasionally (Table 3). The majority of respondents working in government and military hospitals reported that they did not refer patients to PT departments at all.

Sixty-seven percent of respondents with 1-5 years of experience and 13\% respondents with 11-15 years of experience reported regularly referring patients to PT departments. In relation to respondents' specialty, 29\% from medicine, $21 \%$ from surgery, $13 \%$ from orthopedics, $11 \%$ from pediatrics and $9 \%$ from gynecology reported regularly referring patients to PT 
departments.

Perceptions and beliefs of participants about PT as a profession: Among the 280 participants, $44 \%$ of the respondents reported that PT is a professional course, while the remainder either thought that it was not a professional course or that they were not aware of its status. Overall, 58\% reported a negative perception about PT (Table 4). Although $75 \%$ of the respondents reported believing that physical therapists are well trained to take decisions regarding patient treatment, $20 \%$ of respondents still reported include prescriptions in their referrals. Among those who received some training or attended awareness lectures about PT, $20 \%$ and $9 \%$ of respondents respectively reported that they did not include prescriptions in their referrals (Tables 5 and 6). At least 55\% of respondents reported that they were not comfortable about referring patients to PT departments without prescriptions.

\section{DISCUSSION}

This study was done to assess the awareness, perceptions and beliefs about PT among physicians working in SA. The majority of the respondents were from the central region of SA, where the highest number of hospitals and rehabilitation centers are located. The results show that although there was moderate awareness about PT among the respondents, there was

Table 1. Demographic characteristics of respondents: number and percentage

\begin{tabular}{lc}
\hline Work hospitals & $\mathrm{N}(\%)$ \\
\hline Government & $84(30)$ \\
Military & $57(20)$ \\
Educational & $47(17)$ \\
National guard & $36(13)$ \\
Primary care & $56(20)$ \\
Experience & \\
$<5$ & $140(50)$ \\
$5-20$ years & $100(36)$ \\
$>20$ years & $40(14)$ \\
Specialty & \\
Orthopedics & $30(11)$ \\
Pediatrics & $15(5)$ \\
Gynecology & $12(4)$ \\
Surgery & $29(10)$ \\
Emergency & $15(5)$ \\
Neurology & $25(9)$ \\
Medicine & $39(14)$ \\
Radiology & $12(4)$ \\
General practitioners & $103(37)$ \\
\hline
\end{tabular}

Table 3. Referral of patients to a physiotherapy department: number and percentage

\begin{tabular}{lr}
\hline Referral to PT department & N (\%) \\
\hline Do no refer at all & $138(49)$ \\
Rarely refer & $72(26)$ \\
Refer occasionally & $40(14)$ \\
Refer regularly & $30(11)$ \\
\hline
\end{tabular}

Table 4. Reasons for respondents' negative perceptions about physiotherapy

\begin{tabular}{lc}
\hline $\begin{array}{l}\text { Causes of negative perception about } \\
\text { physiotherapy }\end{array}$ & Percentage \\
\hline $\begin{array}{l}\text { Because I do not know much about } \\
\text { physiotherapy training }\end{array}$ & 17 \\
$\begin{array}{l}\text { Because physiotherapy is complimentary } \\
\text { to medicine }\end{array}$ & 61 \\
$\begin{array}{l}\text { Because physiotherapy doesn't have } \\
\text { enough scientific basis }\end{array}$ & 22 \\
\hline
\end{tabular}

Table 2. Educational background of respondents in comparison to their referral rate: percentage

\begin{tabular}{|c|c|c|c|c|}
\hline \multirow[b]{2}{*}{ Attended a lecture about physiotherapy } & \multicolumn{4}{|c|}{ Referral rate } \\
\hline & Not at all & Rarely & Occasionally & Regularly \\
\hline Yes & $51.1 \%$ & $19.1 \%$ & $14.9 \%$ & $14.9 \%$ \\
\hline No & $48.9 \%$ & $27 \%$ & $14.2 \%$ & $9.9 \%$ \\
\hline \multicolumn{5}{|c|}{ Received special training on cases that benefit from physiotherapy } \\
\hline Yes & $41.3 \%$ & $30.6 \%$ & $35 \%$ & $20 \%$ \\
\hline No & $58.7 \%$ & $69.4 \%$ & $65 \%$ & $80 \%$ \\
\hline \multicolumn{5}{|c|}{ Had physiotherapy facilities in medical school } \\
\hline Yes & $34.1 \%$ & $40.3 \%$ & $27.5 \%$ & $50 \%$ \\
\hline No & $42.8 \%$ & $37.5 \%$ & $52.5 \%$ & $36.7 \%$ \\
\hline Not sure & $23.2 \%$ & $22.2 \%$ & $20 \%$ & $13.3 \%$ \\
\hline
\end{tabular}


variation in the referral of patients to PT departments, which was dependent on physicians' specialty and work experience.

Compared to similar studies around the world ${ }^{3,8,11,13)}$, the referral rate in SA is low. This shows that awareness about the importance of PT treatment is unable to convince respondents to refer patients to PT departments when required. However, respondents who received some training or attended lectures about awareness of PT reported referring more patients than their counterparts. This highlights the need for organizing various workshops and lectures for physicians about the effectiveness of PT for various conditions, on a regular basis, to update physicians with evidence-based PT treatments ${ }^{14)}$. This would in turn increase physicians' confidence in PT and encourage referrals to PT department ${ }^{5,8}$.

Traditionally, physical therapists have more often been seen as technicians subordinate to physicians with no freedom to evaluate, diagnose or decide treatments for the patients ${ }^{2,12}$. However, things have changed recently. Our results show that awareness about PT is higher among respondents with work experience of 1-5 years than among those with more experience. This indicates the growth of PT as a profession in recent times. With the advancement of information and technology, young respondents seem to have more knowledge about PT. The results also show that respondents reported that they were more aware of PT if it had been offered as a course at their graduating institution.

Little difference was found in awareness and patient referrals among respondents working in different hospitals. Patient referrals may be lower in government hospitals due to their higher patient load ${ }^{5)}$ and lack of staff and facilities.

Despite rising awareness, most of the respondents reported that they refer patients with a 'prescription'. This mode of referral, although practiced for long ${ }^{12}$ ), has been widely criticized in the developed countries as a mistaken attitude of physicians towards physical therapists ${ }^{15}, 16$. Moreover, prescriptions written by physicians contain differential diagnosis and treatment orders ${ }^{8}$, most of which are often found to be wrong ${ }^{17)}$. Physical therapists' first contact with the patient is now widely practiced in countries like the UK and Australia ${ }^{18-20}$. The majority of insurance companies reimburse for PT services only if it is prescribed by physicians, which could be another reason for the upper hand of physicians over physical therapists $^{21)}$. Although some respondents reported that they considered PT is an independent branch of medicine, and that physical therapists were sufficiently qualified for clinical decision making, first contact of patient with physical therapists is still not common in Saudi Arabia. Physicians seem to hesitate to allow them to work independently.

It has been shown in various studies around the world that physicians have limited knowledge about the role of PT in the healthcare system ${ }^{12,22)}$. Physical therapists need to raise their professional image themselves. This can be achieved by pursuing advanced studies and involving themselves more in research. More interaction with fellow physicians ${ }^{23)}$ to discuss evidence-based treatment and prognosis of patients' conditions also needs to be encouraged ${ }^{5,24)}$.

The results of this study also highlight the need for research about PT services available in different hospitals, especially in rural areas. A similar study with a larger sample and equal representation of physicians' experience should be done in order to find if awareness about the professional image of PT has changed over the past few decades.

To the best of our knowledge, this is first study conducted in Saudi Arabia to evaluate the awareness of physicians about the physiotherapy profession. Despite considerable awareness about the PT profession among physicians in SA, the rate of referral of patients to PT departments for treatment is poor. It is the responsibility of physical therapists to upgrade the perception of other members of healthcare teams about their profession.

Table 5. Respondents' view on the ability of physical therapists to deduce treatment in relation to receiving special training: number and percentage

\begin{tabular}{ccccc}
\hline & \multicolumn{3}{c}{ Received special training } \\
\cline { 2 - 5 } Ability of physiotherapist to deduce patients' treatment & \multicolumn{3}{c}{ Yes } & No \\
\hline Yes & 73 & $26.1 \%$ & 137 & $48.9 \%$ \\
No & 26 & $9.3 \%$ & 44 & $15.7 \%$ \\
\hline
\end{tabular}

Table 6. Respondents who attended awareness lectures or workshops about physiotherapy and their referrals with or without prescriptions: number and percentage

\begin{tabular}{lllll}
\hline & \multicolumn{4}{c}{ Including prescription } \\
\cline { 3 - 5 } Received special training on cases that benefit from physiotherapy & \multicolumn{3}{c}{ Yes } & No \\
\hline Yes & 46 & $16.4 \%$ & 53 & $18.9 \%$ \\
No & 56 & $20 \%$ & 125 & $44.6 \%$ \\
\hline Attended lecture about physiotherapy & & & & \\
\hline Yes & 23 & $8.2 \%$ & 24 & $8.6 \%$ \\
No & 79 & $28.2 \%$ & 154 & $55 \%$ \\
\hline
\end{tabular}




\section{Conflict of interest}

The authors have no conflict of interest to declare.

\section{ACKNOWLEDGEMENT}

This study was fully financially supported by the King Saud University, through the Vice Deanship of Research Chairs, Rehabilitation Research Chair.

\section{REFERENCES}

1) Murphy BP, Greathouse D, Matsui I: Primary care physical therapy practice models. J Orthop Sports Phys Ther, 2005, 35: 699-707. [Medline] [CrossRef]

2) James JJ, Stuart RB: Expanded role for the physical therapist. Screening musculoskeletal disorders. Phys Ther, 1975, 55: 121-131. [Medline]

3) Silva DM, Clark SD, Raymond G: California physician's professional image of therapists. Phys Ther, 1981, 61: 1152-1157. [Medline]

4) Sran MM, Murphy S: Postgraduate physiotherapy training: interest and perceived barriers to participation in a clinical master's degree programme. Physiother Can, 2009, 61: 234-243. [Medline] [CrossRef]

5) Kerssens JJ, Groenewegen PP: Referrals to physiotherapy: the relation between the number of referrals, the indication for referral and the inclination to refer. Soc Sci Med, 1990, 30: 797-804. [Medline] [CrossRef]

6) Al-Jadid MS: Disability in Saudi Arabia. Saudi Med J, 2013, 34: 453-460. [Medline]

7) Alghadir A, Zafar H, Iqbal ZA, et al.: Physical therapy education in Saudi Arabia. J Phys Ther Sci, 2015, 27: 1621-1623. [Medline] [CrossRef]

8) Clawson AL, Domholdt E: Content of physician referrals to physical therapists at clinical education sites in Indiana. Phys Ther, 1994, 74: 356-360. [Medline]

9) Lee K, Sheppard L: An investigation into medical students' knowledge and perception of physiotherapy services. Aust J Physiother, 1998, 44: 239-245. [Medline] [CrossRef]

10) Blair DC: Allied health professions and the non-physician-referred practice of physiotherapy. Can Med Assoc J, 1979, 120: 519-520. [Medline]

11) Odebiyi DO, Omotunde AO, Aiyejusunle CB, et al.: Knowledge and perception of physiotherapy by final year medical students of a Nigerian university. Nig Q J Hosp Med, 2008, 18: 156-161. [Medline]

12) Liu H, Fletcher JP: Analysis of physicians' referrals: is further diagnosis needed? N Am J Sports Phys Ther, 2006, 1: 10-15. [Medline]

13) Harrison FG, Kisicki DS: How knowledgeable are physician assistants and nurse practitioners about physical therapy? J Allied Health, 2006, 35: e227-e239. [Medline]

14) Fertig A, Roland M, King H, et al.: Understanding variation in rates of referral among general practitioners: are inappropriate referrals important and would guidelines help to reduce rates? BMJ, 1993, 307: 1467-1470. [Medline] [CrossRef]

15) Kersten P, McPherson K, Lattimer V, et al.: Physiotherapy extended scope of practice — who is doing what and why? Physiotherapy, 2007, 93: 235-242. [CrossRef]

16) Uili RM, Shepard KF, Savinar E: Physician knowledge and utilization of physical therapy procedures. Phys Ther, 1984, 64: 1523-1530. [Medline]

17) Maxwell M, Dickson DA, Saunders C: An evaluation of communication skills training for physiotherapy students. Med Teach, 1991, 13: 333-338. [Medline] [CrossRef]

18) Sheppard L: Changing the public perception of physiotherapeutic treatment. Health Mark Q, 1994, 12: 77-95. [Medline] [CrossRef]

19) Anaf S, Sheppard LA: Lost in translation? How patients perceive the extended scope of physiotherapy in the emergency department. Physiotherapy, 2010, 96: 160-168. [Medline] [CrossRef]

20) Leemrijse CJ, Swinkels IC, Veenhof C: Direct access to physical therapy in the Netherlands: results from the first year in community-based physical therapy. Phys Ther, 2008, 88: 936-946. [Medline] [CrossRef]

21) Jette AM, Davis KD: A comparison of hospital-based and private outpatient physical therapy practices—response. Phys Ther, 1991, 71: 380-381.

22) Waldman M: Conflict of interest, physicians and physiotherapy. CMAJ, 1996, 154: 1737-1739. [Medline]

23) Rothstein JM: Autonomy or professionalism? Phys Ther, 2003, 83: 206-207. [Medline]

24) Massey BF Jr: Making vision 2020 a reality. Phys Ther, 2003, 83: 1023-1026. [Medline] 